\title{
Lymphocyte Responses to Chymotrypsin- or Trypsin V- Digested $\beta$-Lactoglobulin in Patients with Cow's Milk Allergy
}

\author{
Masashi Kondo, MD, PhD, Toshiyuki Fukao, MD, PhD, Shinji Shinoda, MD, PhD, Norio Kawamoto, MD, PhD, \\ Hideo Kaneko, MD, PhD, Zenichiro Kato, MD, PhD, Eiko Matsui, MD, PhD, Takahide Teramoto, MD, PhD, \\ Taku Nakano, PhD, and Naomi Kondo, MD, PhD
}

\begin{abstract}
Chymotrypsin- or trypsin V- (a mixture of trypsin and chymotrypsin) digested $\beta$-lactoglobulin (BLG) peptides were prepared and were confirmed to have much less immunoglobulin $(\mathrm{Ig}) \mathrm{G}$ and $\mathrm{IgE}$ reactivity compared with intact BLG by IgG inhibition enzymelinked immunosorbent assay and IgE dot blotting. The lymphocyte responses to intact BLG and these peptides were examined using peripheral blood mononuclear cells (PBMCs) from 10 patients with cow's milk allergy. The PBMCs from most patients had lower lymphocyte responses to chymotrypsin- and trypsin V-digested BLG peptides than those to intact BLG. However, PBMCs from one and two patients retained significant proliferative responses to both peptides and to only the former peptide, respectively. Interferon- $\gamma$ production stimulated by chymotrypsin-digested peptides was still detectable in all five patients tested. Chymotrypsindigested BLG reduced IgE reactivity but still induced some lymphocyte responses.
\end{abstract}

$C$ ow's milk is one of the most common food allergens in the first year of life, with approximately 2 to $2.5 \%$ of infants experiencing allergic reactions to it. The majority of children outgrow their allergy to cow's milk before the age of 3 years, but $15 \%$ of infants with immunoglobulin (Ig)E-mediated cow's milk allergy retain their sensitivity into the second decade. ${ }^{1,2}$

The therapy for food allergy is a problem that is still to be resolved. The first therapeutic approach to patients with cow's milk allergy is elimination from the diet of cow's milk proteins. However, this is not always easy because cow's milk is an essential constituent of the diet or can be found in other foods as a hidden allergen. Moreover, elimination from the diet may cause nutritional imbalance.

Specific allergen immunotherapy has been shown to be effective in modulating allergic responses in diseases such as rhinitis and asthma. ${ }^{3,4}$ However, the ability of whole

M. Kondo, T. Fukao, S. Shinoda, N. Kawamoto, H. Kaneko, Z. Kato, E. Matsui, T. Teramoto, N. Kondo: Department of Pediatrics, Graduate School of Medicine, Gifu University, Gifu, Japan; T. Nakano-Research and Development Department, Bean Stalk Snow Co., Ltd, Kawagoe, Japan.

Correspondence to: Masashi Kondo, MD, Department of Pediatrics, Graduate School of Medicine, Gifu University, Yanagido 1-1, Gifu, Gifu 501-1194, Japan; e-mail: g2104012@guedu.cc.gifu-u.ac.jp.

DOI 10.2310/7480.2006.00014 cow's milk to crosslink mast cell-bound IgE, resulting in anaphylactic reaction, has limited the application of rush immunotherapy with intact cow's milk.

A possible immunotherapeutic approach to cow's milk allergy would be the use of hydrolyzed or enzymatically digested peptides of cow's milk, which can induce immunomodulation by T-cell response but which do not cause IgE-mediated reactions. Even the use of hydrolyzed or digested peptides can cause IgE-mediated reactions if IgE epitopes are still present in the digested peptides. On the other hand, T-cell epitopes may not be retained by hydrolysis or digestion. In the latter case, no immunomodulation is expected.

Generally, IgE antibodies to the various allergen components in cow's milk proteins (such as casein and whey proteins) are present in patients with cow's milk allergy. One of the major allergens in cow's milk is $\beta$ lactoglobulin (BLG). It has no homologous counterpart in human milk. In rodents, partially hydrolyzed whey protein and trypsin-digested BLG induced specific immunologic tolerance to BLG. ${ }^{5,6}$ These data in mice encouraged us to use enzymatically digested peptides of BLG to induce immunologic tolerance in patients with cow's milk allergy.

In this study, two kinds of BLG peptides digested by chymotrypsin alone or trypsin $\mathrm{V}$ (a combination of chymotrypsin and trypsin) were prepared and reduced IgE reactivity was confirmed. For the first step of a possible 
immunotherapy using these peptides, we analyzed the proliferative response of peripheral blood mononuclear cells (PBMCs) to intact BLG and to these digested peptides in 10 patients with cow's milk allergy.

\section{Materials and Methods}

\section{Subjects}

Fourteen healthy children (age 4 months-12 years; mean age 3.9 years) without cow's milk allergy and 10 children with cow's milk allergy (age 1-6 years; mean age 4.1 years) were studied. Allergic symptoms such as urticaria, erythema, and wheezing occurred in less than 1 hour after cow's milk ingestion in these allergic patients (Table 1). The diagnosis of allergy to cow's milk was based on clinical symptoms after ingestion, including an open challenge test and cow's milk-specific IgE measured by CAPRAST (Sweden Diagnostics). Cow's milk proteins were eliminated from the diets of these patients at the time of investigation.

\section{Preparation of Enzyme-Digested BLG Peptides}

The digested peptide fragments were prepared from BLG (Lot 51 H7210, Sigma, St Louis, MO) or edible BLG (WPI, Auckland, New Zealand) as follows. BLG extracts (5 mg/ $\mathrm{mL}$ ) were incubated for 6 hours at $40^{\circ} \mathrm{C}$ with trypsin $\mathrm{V}$ (Biocon Japan, Nagoya, Japan) or chymotrypsin (MP Biomedicals, Irvine, CA) at a final enzyme concentration of $0.1 \mathrm{mg} / \mathrm{mL}$. After digestion, the enzymes were inactivated by incubation for 10 minutes at $100^{\circ} \mathrm{C}$.

\section{Sodium Dodecyl Sulphate-Polyacrylamide gel Electrophoresis Analysis of Cow's Milk, BLG, and Peptides}

Twenty-microlitre samples of cow's milk $(5 \mu \mathrm{g})$, BLG $(1 \mu \mathrm{g})$, and the digested BLG fragments $(1 \mu \mathrm{g})$ were electrophoresed on a 10 to $20 \%$ gradient sodium dodecyl sulphate (SDS)—polyacrylamide gel at $20 \mathrm{~mA}$ of constant current until the tracking dye reached the bottom of the gel. The polypetides were visualized by Coomassie blue staining.

\section{High-Performance Liquid Chromatography Gel Filtration of the Digested Peptides}

The preparations were subjected to high-performance liquid chromatography gel filtration to analyze the molecular weight distribution of the digested peptides. The preparations were applied to TSKgelG3000PW $\mathrm{XL}$ (TOHO, Tokyo, Japan) and eluted with $0.1 \%$ trifluoroacetic acid and 55\% acetonitrile. The column was calibrated using standard proteins for molecular weights as follows: $\alpha$-casein $(24.5 \mathrm{kD})$, BLG $(18.3 \mathrm{kD}), \alpha$ lactalbumin $(14.2 \mathrm{kD})$, aprotinin $(6.5 \mathrm{kD}), \beta$-chain of insulin $(3.5 \mathrm{kD})$, angiotensin II $(1.0 \mathrm{kD})$, and glutathione $(0.3 \mathrm{kD})$. The molecular weight of the peptides was estimated using a calibration curve, plotting the logarithm of the molecular weight against retention time.

\section{IgG Inhibition Enzyme-Linked Immunosorbent Assay}

A 96-well microtitre plate (Maxisorp, NUNC, Denmark) was coated with $100 \mu \mathrm{L}$ of intact BLG at $1 \mu \mathrm{g} / \mathrm{mL}$ in $0.05 \mathrm{M}$

Table 1. Characterization of Allergic Patients

\begin{tabular}{|c|c|c|c|c|c|c|c|c|}
\hline \multirow[b]{2}{*}{ Patient } & \multirow[b]{2}{*}{ Sex } & \multirow[b]{2}{*}{ Age (yr) } & \multirow{2}{*}{$\begin{array}{l}\text { Symptoms Caused by } \\
\text { Cow's Milk Intake }\end{array}$} & \multirow[b]{2}{*}{$B A$} & \multirow[b]{2}{*}{$A D$} & \multirow[b]{2}{*}{$\operatorname{IgE}(I U / m L)$} & \multicolumn{2}{|c|}{ CAP-RAST Values } \\
\hline & & & & & & & Milk & $B L G$ \\
\hline 1 & $\mathrm{M}$ & 3 & Erythema & - & + & 2,200 & 0.78 & 0.37 \\
\hline 2 & $\mathrm{~F}$ & 2 & Vomiting, wheezing & + & + & 5,000 & $>100.0$ & 2.0 \\
\hline 3 & $\mathrm{M}$ & 5 & Wheezing & + & - & 1,500 & 67.0 & 12.0 \\
\hline 4 & $\mathrm{M}$ & 6 & Wheezing, urticaria & + & - & 88 & 4.0 & $<0.34$ \\
\hline 5 & $\mathrm{~F}$ & 4 & Wheezing & + & - & 120 & 0.92 & $<0.34$ \\
\hline 6 & $\mathrm{M}$ & 4 & Wheezing, urticaria & + & + & 600 & 1.2 & 0.52 \\
\hline 7 & $\mathrm{M}$ & 6 & Wheezing, urticaria & + & + & 510 & $>100.0$ & 5.2 \\
\hline 8 & $\mathrm{~F}$ & 2 & Wheezing, urticaria & + & - & 470 & 16.0 & $<0.34$ \\
\hline 9 & $\mathrm{M}$ & 1 & Erythema & + & + & 190 & 10.0 & 0.86 \\
\hline 10 & $\mathrm{M}$ & 3 & Wheezing, urticaria & + & + & 100 & 13.0 & 1.0 \\
\hline
\end{tabular}

$\mathrm{AD}=$ atopic dermatitis; $\mathrm{BA}=$ bronchial asthma; $\mathrm{BLG}=\beta$-lactoglobulin; $\mathrm{IG}=$ immunoglobulin . 
sodium bicarbonate ( $\mathrm{pH} 9.0$ ) overnight at room temperature. After washing four times with $0.1 \%$ Tween 20 in phosphate-buffered saline (PBST), blocking was done with $0.4 \%$ goat serum for 90 minutes at room temperature. After washing four times with PBST, the wells were incubated with rabbit anti-BLG antisera $(50 \mu \mathrm{L}, 1: 64,000$ dilution) and $50 \mu \mathrm{L}$ of serially diluted samples (intact BLG, enzyme-digested polypeptides) for 90 minutes at room temperature. After washing four times with PBST, the wells were incubated with a peroxidase-conjugated antirabbit IgG antibody (goat) (1:10,000 dilution). After washing four times with PBST, the plate was developed with a peroxidase substrate buffer. After 15 minutes, the reaction was stopped with $25 \mu \mathrm{L}$ of $4 \mathrm{~N} \mathrm{H}_{2} \mathrm{SO}_{4}$ and the OD was measured at $490 \mathrm{~nm}$. The percentage of inhibition was calculated as (total reactivity - remaining reactivity after absorption) $\times 100 /$ total reactivity.

\section{IgE Dot Blotting}

Twenty micrograms of protein was applied onto nitrocellulose filter paper $(0.2 \mu \mathrm{m}$, BioRad, CA $)$. After washing and blocking with $5 \%$ bovine serum albumin (BSA) in $\mathrm{PBS}$, the membranes were incubated with sera from controls who had no specific IgE for cow's milk or BLG or patient 2, who had specific IgE for BLG (1:20 dilution). The membranes were then treated with alkaline phosphatase-conjugated monoclonal antihuman IgE (GE-1, Sigma, 1:500 dilution) and colour-developed by a 5-bromo-4chloro-3-indol phosphate and nitro blue tetrazolium solution (Sigma).

\section{Antigen-Induced Proliferative Responses of the PBMCs}

PBMCs were isolated from heparinized blood from control donors and patients by gradient centrifugation in FicollPaque (Pharmacia AB, Uppsala, Sweden). PBMCs were cultured with BLG or the digested peptides at a concentration of $20 \mu \mathrm{g} / \mathrm{mL}$ at $37^{\circ} \mathrm{C}$ in a $5 \% \mathrm{CO}_{2^{-}}$ humidified atmosphere for 5 days. Proliferative responses to food antigens were performed as previously described. ${ }^{7}$ Briefly, these assays were performed in triplicate in 96-well, flat-bottomed microtitre plates (Nunclon, Roskike, Denmark) by using $2 \times 10^{5}$ cells per well in a total volume of $200 \mu \mathrm{L}$. The culture medium consisted of RPMI 1640 (Sanko Junyaku Co., Ltd, Tokyo, Japan) supplemented with $10 \%$ pooled human $\mathrm{AB}$ serum (Cambrex Bio Science Walkersville Inc., Walkersville, MD), L-glutamine $(2 \mathrm{mmol} / \mathrm{L})$, penicillin $(100 \mathrm{IU} / \mathrm{mL})$, and streptomycin
(100 $\mu \mathrm{g} / \mathrm{mL})$. Proliferation was measured by [3H]thymidine incorporation $(0.5 \mu \mathrm{Ci} /$ well $)$ during the last 16 hours of culture. Proliferation response was measured as the stimulation index (SI) by using the following formula: counts per minute $(\mathrm{cpm})$ incorporated into antigen-stimulated cultures/cpm incorporated into medium control.

\section{Antigen-Induced Interferon- $\gamma$ Production}

Culture supernatants of PBMCs stimulated with intact BLG or the digested peptides for 5 days, as described above, were spun to remove PBMCs and the supernatants were frozen at $-30^{\circ} \mathrm{C}$ until assay. Interferon- $\gamma($ IFN $-\gamma)$ concentration was measured with the use of a human IFN- $\gamma$ enzyme-linked immunosorbent assay (ELISA) kit (JIMRO, Takasaki, Japan); the detection limit was $15.6 \mathrm{pg} / \mathrm{mL}$.

\section{Statistical Analysis}

Student's $t$-test was used to determine significant differences in the SI between healthy controls and subjects with cow's milk allergy.

\section{Results}

\section{Subjects}

As shown in Table 1, we analyzed 10 patients with cow's milk allergy. Allergic symptoms such as urticaria, erythema, and wheezing occurred in less than 1 hour after cow's milk ingestion in these patients. All patients had cow's milk-specific IgE, and seven of them had BLGspecific IgE, examined by CAP-RAST.

\section{Preparation of BLG Peptides Digested by Chymotrypsin or Trypsin V}

We focused on the allergenicity of BLG and made two kinds of BLG peptides. We used chymotrypsin and trypsin $\mathrm{V}$ to make BLG peptides. Trypsin $\mathrm{V}$ is a mixture of chymotrypsin and trypsin. Figure 1 shows the digestive sites of BLG polypeptides by these enzymes. Digestion with chymotrypsin resulted in small peptides ranging from 3- to 31-amino acid residues whereas digestion with trypsin $\mathrm{V}$ produced smaller peptides ranging from 1- to 20-amino acid residues. As expected, these digested polypeptides were hardly visualized by 10 to $20 \%$ gradient SDSpolyacrylamide gel electrophoresis (Figure $2 \mathrm{~A}$ ). Figure $2 \mathrm{~B}$ 
Chymotrypsin

LIVTQTMKGLDIQKVAGTW|Y|SLAMAASDISLLDAQSAPLRVY $\mid$ VEELKPTPEGDLEILLQKW] ENDECAQKKIIAEKTKIPAVF|KIDA LNENKVLVLDTDY|KKY|LLF|CMENSAEPEQSLVCQCLVRTPEV DDEALEKF|DKALKALPMHIRLSF|NPTQLEEQCHI

Trypsin $\mathrm{V}$

LIVTQTMK] GLDIQK]|VAGTW|Y|SLAMAASDISLLDAQSAPLR]|VY| VEELK]|PTPEGDLEILLQK]|W| ENDECAQK|K|[IAEK|TKK)]IPAVF]|K] IDALNENK|VLVLDTDY $|K| K \mid$ Y Y LLF CMENSAEPEQSLVCQCLVR》 TPEVDDEALEK]F PK/ALK]ALPMHIR]LSF|NPTQLEEQCHI

Figure 1. $\beta$-Lactoglobulin peptide fragments generated by chymotrypsin or trypsin V digestion. Digestive sites by chymotrypsin and trypsin are shown by arrows and open arrows, respectively. Trypsin V is a mixture of chymotrypsin and trypsin.

shows the results of gel filtration column chromatography of intact BLG and its digested peptides by these proteases. Both preparations retained polypeptides with a molecular weight of around $1.6 \mathrm{kD}$. We used these peptides for further analyses.

\section{IgG and IgE Binding Capacity of BLG Polypeptides}

We first confirmed the reduced antigenicity of these BLG polypeptides by IgG inhibition ELISA using rabbit antiBLG antisera (Figure 3A). Intact BLG effectively inhibited binding of the anti-BLG antibody in a dose-dependent manner, and both chymotrypsin-digested peptides and trypsin V-digested peptides had similar inhibitory capacities, but they inhibited binding of the anti-BLG antibody much less than intact BLG. As shown in Figure 2A, the digested peptides were too small to separate in SDS-PAGE, so we employed IgE dot blot analysis instead of IgE immunoblot, using the controls' and patient 2's sera. As shown in Figure 3B, IgE binding capacity was reduced in chymotrypsin-digested peptides and trypsin V-digested peptides, compared with intact BLG.

\section{Antigen-Induced Proliferative Responses of the PBMCs}

As shown in Figure 4, the SI with BLG at concentrations of $20 \mu \mathrm{g} / \mathrm{mL}$ in PBMCs from 14 healthy controls without

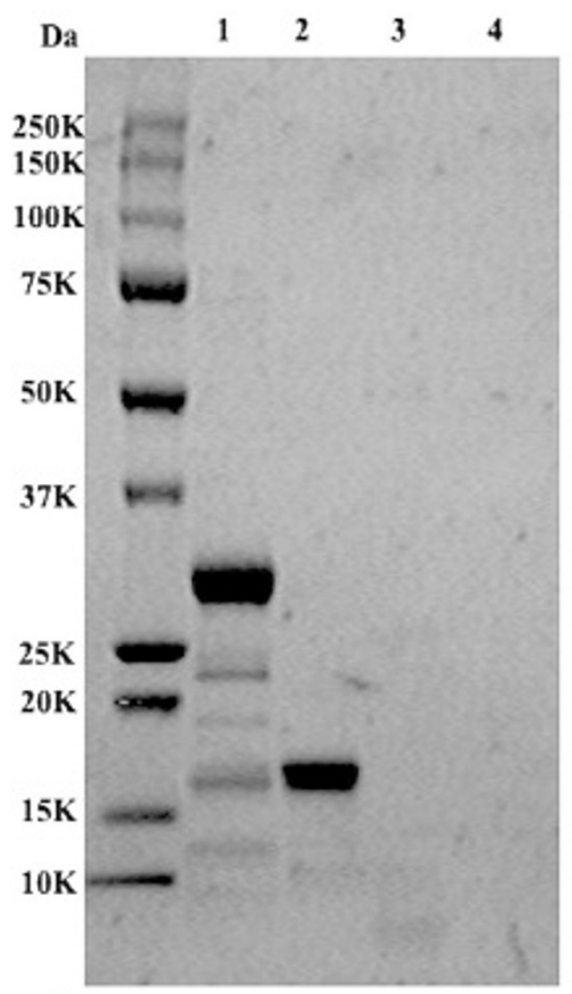

A
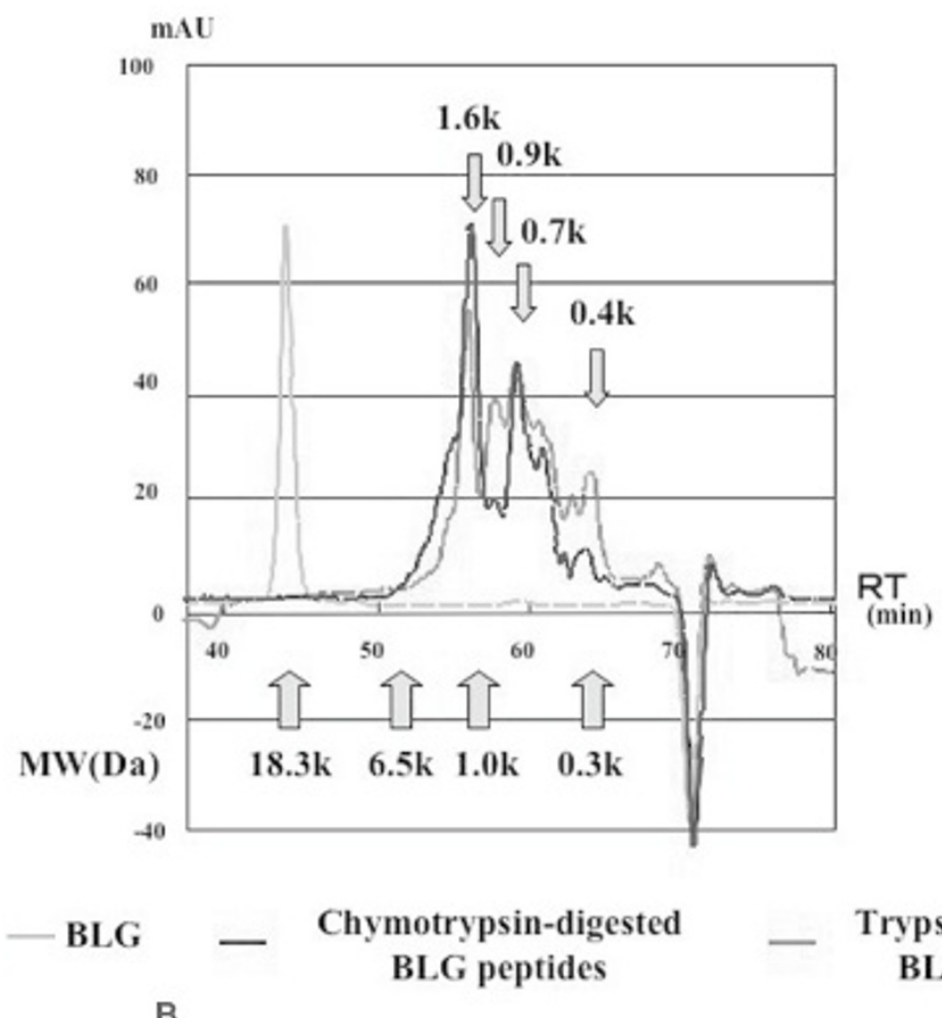

Trypsin V-digested BLG peptides

Figure 2. Characterization of digested $\beta$-lactoglobulin (BLG) peptides. A, Sodium dodecyl sulphate (SDS)-polyacrylamide gel electrophoresis analysis using a 10 to $20 \%$ gradient SDS-polyacrylamide gel. Polypeptides were visualized by Coomassie blue staining. Lane $1,5 \mu \mathrm{g}$ of cow's milk protein; lane 2, $1 \mu \mathrm{g}$ of BLG; lane 3, $1 \mu \mathrm{g}$ of chymotrypsin-digested BLG peptides; lane 4, $1 \mu \mathrm{g}$ of trypsin V-digested BLG peptides. B, Gel filtration analysis of BLG and its digested peptides. Calculated molecular weights for several peaks of peptides are shown above the peaks. 

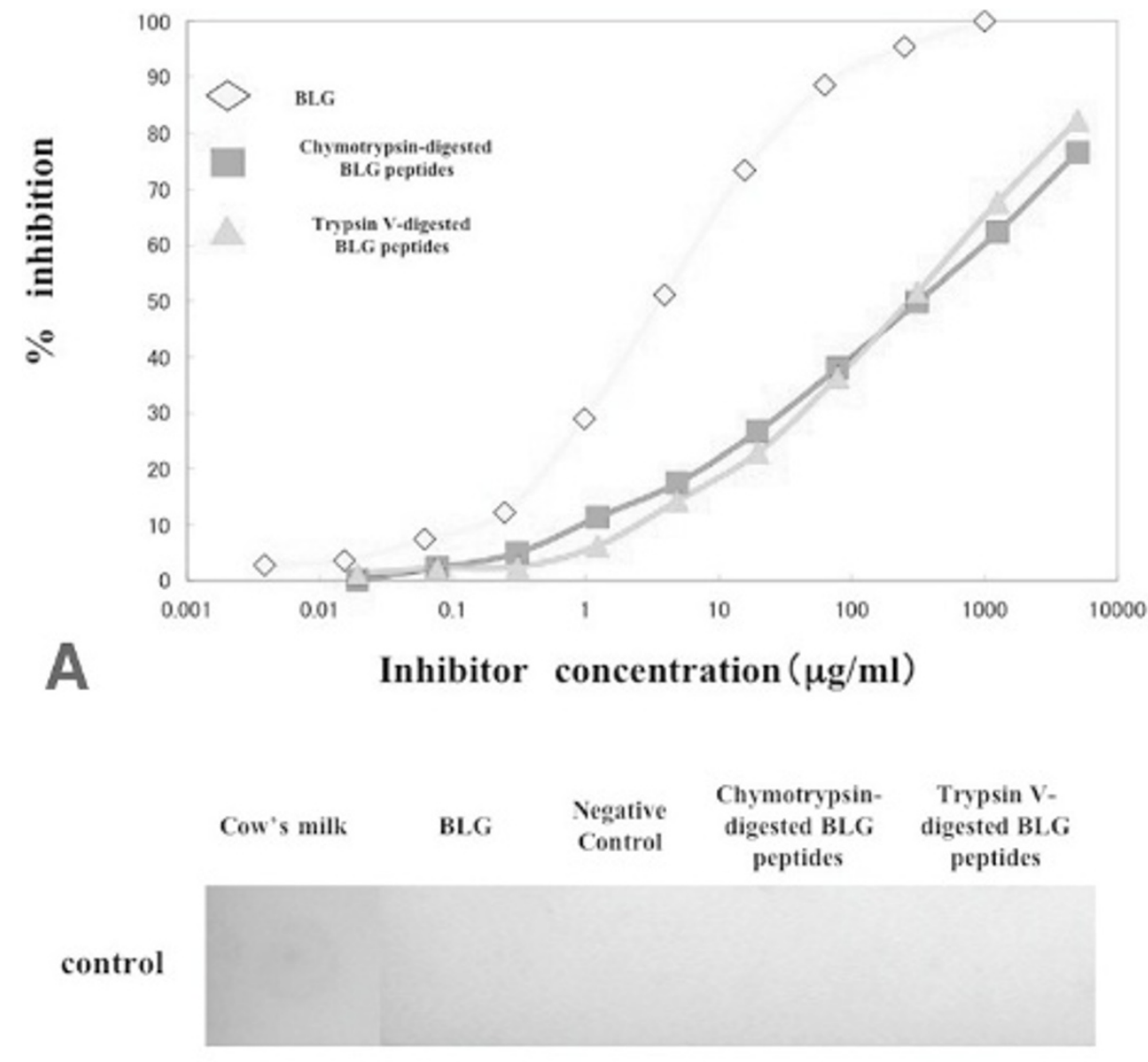

patient 2

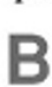

Figure 3. Evaluation of reduced Bcell epitopes in digested peptides. A, Immunoglobulin (Ig) $\mathrm{G}$ inhibition enzyme-linked immunosorbent assay (ELISA). Various amounts of intact $\beta$ lactoglobulin (BLG), chymotrypsindigested BLG polypeptides, or trypsin V-digested polypeptides were co-incubated as inhibitors with rabbit antiBLG antisera in ELISA assay. $B, \operatorname{IgE}$ dot blotting. Twenty micrograms of cow's milk, BLG, extensively hydrolyzed BLG (as a negative control), chymotrypsin-digested BLG polypeptides, and trypsin V-digested BLG polypeptides were applied onto nitrocellulose filter paper. Control and patient 2's sera were used as first antibodies in IgE dot blotting. cow's milk allergy was $1.36 \pm 0.42$. PBMCs from 3 healthy controls and 10 patients with milk allergy were stimulated by intact BLG and the digested peptides. The SI with BLG was significantly higher in PBMCs from all patients than those from healthy controls. These results indicate that the proliferative response to BLG was present even in PBMCs from patients with cow's milk allergy whose CAP-RAST score for BLG was zero. The SI with chymotrypsindigested BLG peptides was much lower than that with intact BLG in PBMCs from all patients except for patient 8. The SI with chymotrypsin-digested peptides in PBMCs from only patients 7,8 , and 9 was significantly higher than that in PBMCs from healthy controls. Moreover, the SI with trypsin $\mathrm{V}$-digested polypeptides tended to be similar to or lower than that with chymotrypsin-digested ones. PBMCs from patients 7 and 9 retained a significantly high SI with chymotrypsin-digested BLG peptides but not with trypsin V-digested BLG polypeptides. PBMCs from patient
8 retained a significantly high SI with trypsin V-digested BLG peptides, as well as chymotrypsin-digested ones.

\section{IFN- $\gamma$ Production from Stimulated PBMCs}

IFN- $\gamma$ production from PBMCs stimulated with intact BLG or chymotrypsin- or trypsin V-digested BLG peptides were also examined (Figure 5). Supernatants of the culture media from 5 of the 10 patients were available for this experiment. IFN- $\gamma$ production by either stimulation was under a detection limit in culture supernatants from a healthy control. IFN- $\gamma$ production was also not detected in supernatants with no stimulation but was induced in supernatants with intact BLG stimulation from all patients tested. IFN- $\gamma$ production by stimulation with the chymotrypsin-digested peptides was less than with intact BLG but was still at detectable levels in supernatants from all patients tested. IFN- $\gamma$ production by stimulation with 


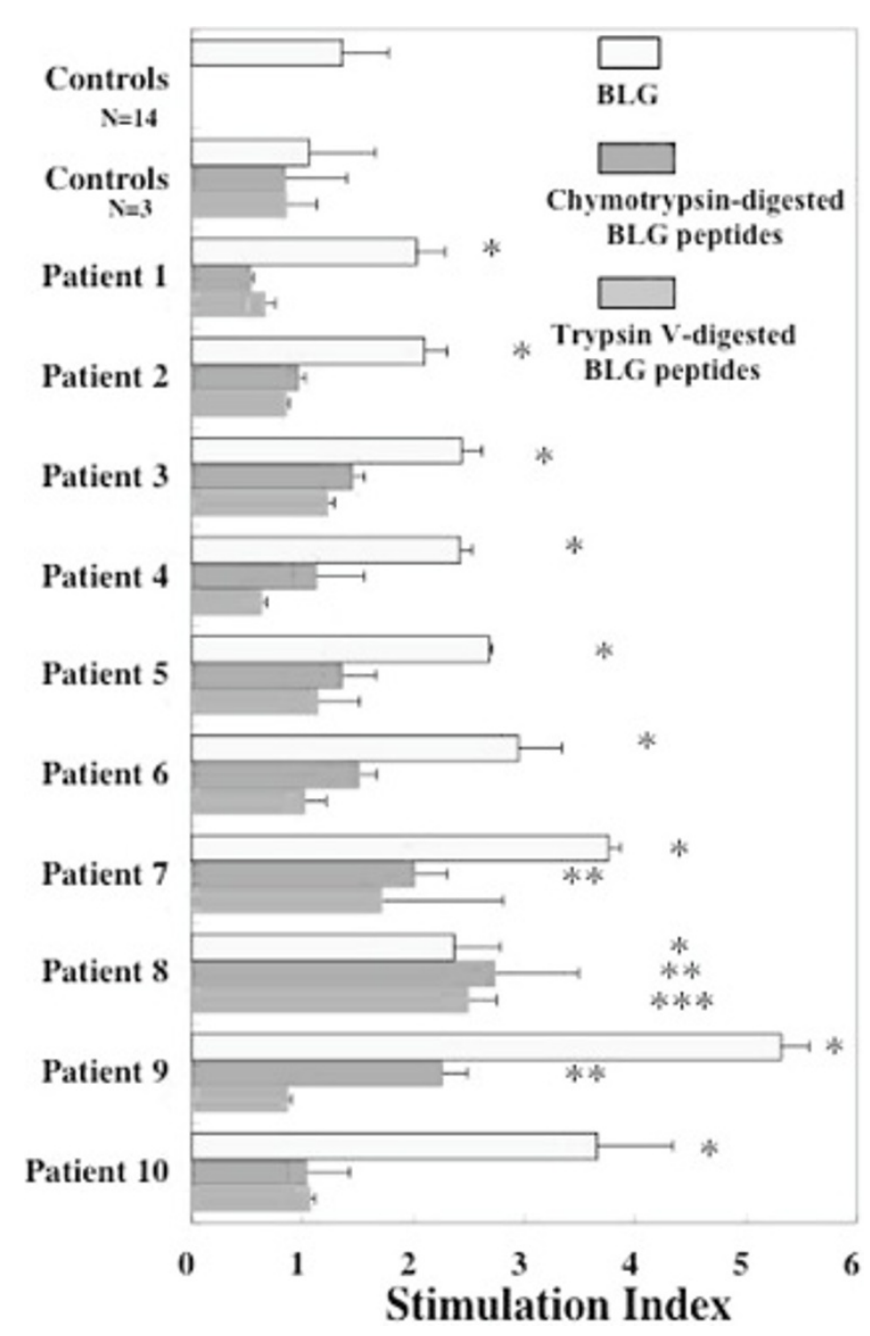

Figure 4. Peripheral blood mononuclear cells' (PBMCs) proliferative response to $\beta$-lactoglobulin (BLG) and digested peptides. PBMCs from 10 patients with cow's milk allergy were stimulated by BLG or digested peptides at a concentration of $20 \mu \mathrm{g} / \mathrm{mL}$ for 5 days. Proliferation was measured by $[3 \mathrm{H}]$-thymidine incorporation during the last 16 hours of culture. Proliferative response is shown as stimulation index. *, **, and $* * *$ indicate significantly higher stimulation index by stimulation with intact BLG, chymotrypsin-digested peptides, and trypsin Vdigested peptides, respectively, than that in healthy controls $(p<.05)$.

trypsin V-digested peptides was under a detection limit in supernatants from patients 6 and 9 .

Taken together, lymphocyte responses to chymotrypsindigested peptides were lower than those to intact BLG in all patients with cow's milk allergy, but lymphocyte responses were still retained significantly in some patients.

\section{Discussion}

In this article, we focused on one of the major allergens, BLG, in cow's milk, made chymotrypsin- or trypsin Vdigested BLG peptides. Then we confirmed reduced IgE

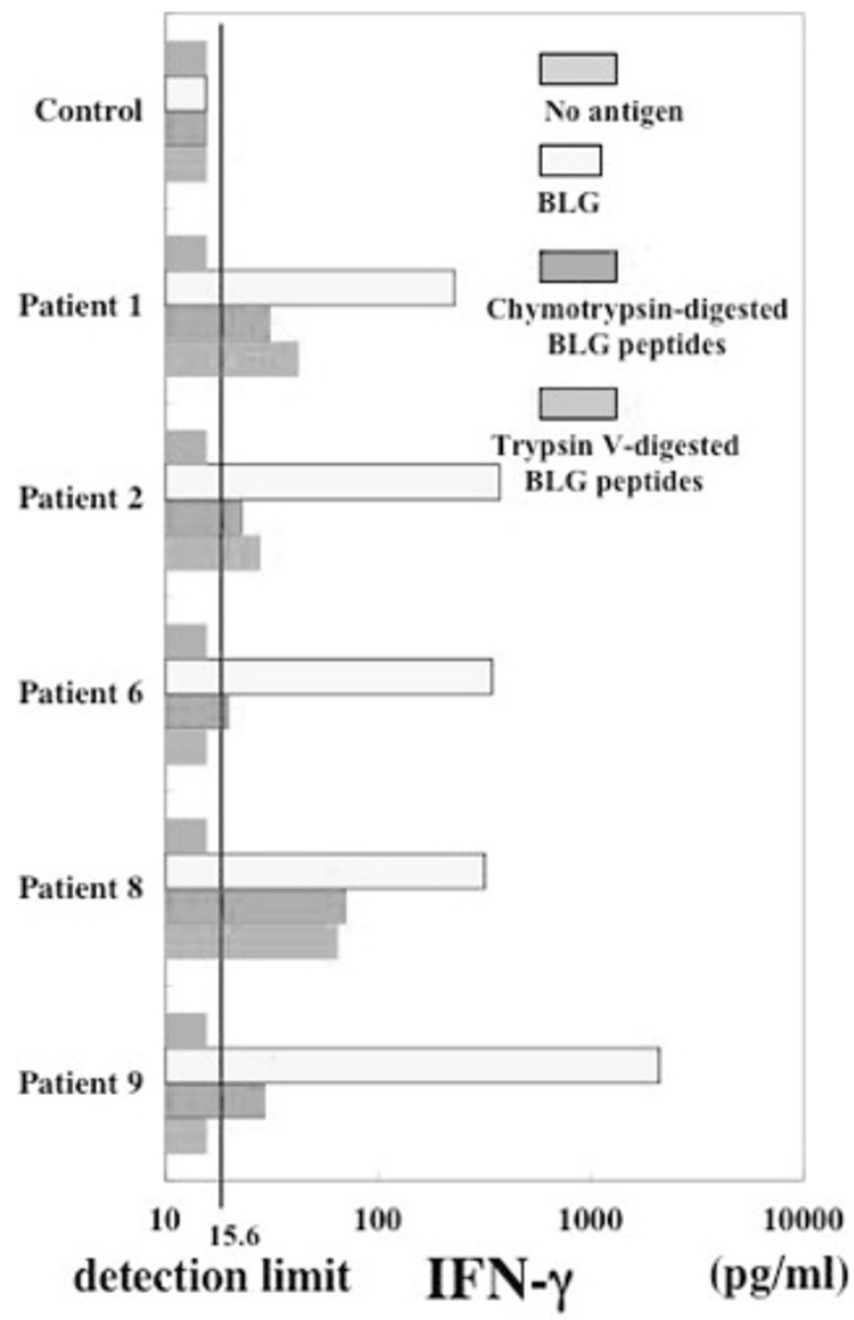

Figure 5. Interferon- $\gamma($ IFN- $\gamma)$ production from peripheral blood mononuclear cells (PBMCs) stimulated by $\beta$-lactoglobulin (BLG) and digested peptides. PBMCs from 5 of the 10 patients with cow's milk allergy were stimulated by BLG or digested peptides at a concentration of $20 \mu \mathrm{g} / \mathrm{mL}$ for 5 days. IFN- $\gamma$ was assayed in the supernatants of cultured PBMCs.

reactivity and analyzed the lymphocyte responses to these peptides compared with the responses to intact BLG in patients with cow's milk allergy as the first step in immunotherapy with enzyme-digested BLG peptides.

Most cases of immediate hypersensitivity to cow's milk are mediated by IgE specific to cow's milk constituents. After a patient with immediate cow's milk hypersensitivity ingests cow's milk, the allergens cross-link cow's milkspecific IgE bound to mast cells or basophils to induce the release of multiple mediators involved in immediate hypersensitivity reactions. The conservative therapeutic approach to such patients is the elimination of cow's milk proteins from the diet. 
The progressive therapy for cow's milk allergy is to induce tolerance by immunomodulation. Oral desensitization using intact cow's milk was reported in a few patients with cow's milk allergy. ${ }^{8}$ It took 4 to 8 months with increasing doses of milk intake. During the desensitization process, some mild side effects, such as angioedema and worsening of atopic dermatitis, were reported. We also performed oral desensitization with a similar protocol and experienced some reactions of immediate hypersensitivity during the therapy (unpublished observation). The ability of whole cow's milk to cross-link mast cell-bound IgE, resulting in anaphylactic reactions, has limited the application of rush immunotherapy with intact cow's milk.

Another possible immunotherapeutic approach to cow's milk allergy would be the use of hydrolyzed or enzymatically digested peptides of cow's milk constituents, which can induce immunomodulation by T-cell response but which do not cause IgE-mediated reactions. There are several formulas for milk allergy. However, the concept for these formulas is quite different from our concept. These formulas were made so as not to induce allergic reactions, so extensive hydrolysis was done to destroy the T-cell epitope and the B-cell epitope. There are several lines of evidence for the effectiveness of such enzyme-digested polypeptides. Chymotrypsin treatment of rye grass pollen induced potent $\mathrm{T}$-cell responses but no B-cell responses in a murine model. ${ }^{9}$ Pepsin-derived fragments of BSA, which preserved T-cell epitopes, favoured immune suppression rather than the helper T-cell function. ${ }^{10}$ The clinical relevance of this approach was also reported in ragweedsensitive patients. ${ }^{11}$ In this study, pepsin-digested ragweed extract was as effective as crude ragweed in the treatment of ragweed-sensitive patients and the immediate skin test activity of the peptic fragments was 1,000-fold less than that of the original crude ragweed. The digested ragweed extract was more effective than the original intact ragweed in relieving clinical symptoms caused by ragweed.

In experimental models, induction of oral tolerance to cow's milk proteins using hydrolyzed peptides of BLG was investigated in detail. ${ }^{12,13}$ In Balb/c mice, the lengths of potentially tolerogenic trypsin-digested BLG peptides were distributed between 8 and 23 amino acids. ${ }^{12}$ Feeding of partially hydrolyzed formulas has been demonstrated to allow the induction of oral tolerance in a rat experimental model whereas extensively hydrolyzed formulas could not. ${ }^{13}$ In the literature, the tolerogenic peptide size is around 20 amino acids. ${ }^{14-16}$ These tolerogenic peptide sizes are in accord with the fact that peptides with 12 to 20 amino acids presented with human leukocyte antigen (HLA) complex class II molecules on the surface of antigen-presenting cells are recognized by $\mathrm{T}$ cells. ${ }^{17}$ The presence of $\mathrm{T}$-cell epitopes is essential for tolerogenic peptides because immunomodulation is induced by $\mathrm{T}$ cells. $^{18}$

We chose BLG as a target protein and chymotrypsin as a digestive protease. BLG is one of the major allergens in cow's milk, and its molecular size is smaller than that of casein. Chymotrypsin digestion gives six peptides with 12to 22-amino acid residues, which may be presented with the HLA type II molecule on antigen-presenting cells and which hence have possible tolerogenic capacities, as discussed above, although a 31-amino acid peptide, an 11-amino acid peptide, two 3-amino acid peptides, and one amino acid are also generated (see Figure 1). Trypsin digestion gives smaller peptides than chymotrypsin digestion (see Figure 1). For the comparison, we also used trypsin V-digested BLG peptides. Since trypsin V contains a mixture of trypsin and chymotrypsin, the resultant peptides were smaller than peptides digested by chymotrypsin or trypsin.

Lymphocyte proliferative response is a useful tool for the evaluation of food allergy, especially food-sensitive atopic dermatitis. ${ }^{7}$ This response requires both $\mathrm{T}$ cells (predominantly CD4 lymphocytes) and monocytes as antigen-presenting cells. ${ }^{19}$ Since lymphocyte proliferative response measures $\mathrm{T}$-cell proliferation, which responds to interaction among HLA class II peptide (T-cell epitope) Tcell receptors, this assay is commonly used for the evaluation of T-cell epitopes. ${ }^{20-25}$ IFN- $\gamma$ is a cytokine produced by $\mathrm{T}$ lymphocytes, which are stimulated by interleukin-12 secreted from antigen-presenting cells. IFN- $\gamma$ secretion from PBMCs is also commonly used for the evaluation of T-cell response to food allergens and their peptides. ${ }^{26-28}$

PBMCs from 10 patients with cow's milk allergy had a significantly higher proliferative response to BLG than those from healthy controls. We first had expected that most PBMCs from these patients could also have given a significant proliferative response to chymotrypsin-digested peptides. However, chymotrypsin digestion reduced lymphocyte proliferation compared with intact BLG in 9 of the 10 patients, and only 3 of them showed significant proliferation. Trypsin V digestion, as expected, reduced a proliferation response more than chymotrypsin digestion. IFN- $\gamma$ production from PBMCs with no stimulation was under a detection limit, but IFN- $\gamma$ production from PBMCs stimulated by the chymotrypsin-digested peptides was detectable in all of the five patients available for this assay. PBMCs from patients 1, 2, and 6 did not show a significant proliferative response to the 
chymotrypsin-digested peptides but had detectable IFN- $\gamma$ production with stimulation by chymotrypsin-digested peptides. These facts suggested that chymotrypsin digestion reduced lymphocyte responses but still retained some T-cell responses in some patients with cow's milk allergy.

In a previous study, we demonstrated that $\mathrm{T}$-cell clones specific to BLG (YA4, HA5.7), which were established from patients with cow's milk allergy, needed, as a minimum, peptide BLGp102-112 (YLLFCMENSAE) when presented with HLA-DRB $1 * 0405$ to proliferate. $^{21}$ Unfortunately, chymotrypsin digestion does not retain this T-cell epitope. This may be one of the reasons why lymphocyte responses to chymotrypsin-digested BLG peptides became lower than those to BLG.

Finally, evaluation of the residual B-cell epitope in chymotrypsin-digested BLG is necessary for the application of immunomodulation therapy with the peptides. We performed inhibition ELISA using rabbit anti-BLG antisera and IgE dot blotting using the sera of patients who had BLG-specific IgE. These experiments clearly showed reduced B-cell epitopes in the digested polypeptides. However, the most reliable evaluation of the absence of the B-cell epitope would be the skin-prick test. We are planning to perform this test prior to clinical application of chymotrypsin-digested BLG peptide therapy.

In conclusion, we made chymotrypsin- or trypsin Vdigested BLG peptides and analyzed the lymphocyte responses (predominantly $\mathrm{T}$-cell responses) to these peptides. Chymotrypsin digestion decreased the lymphocyte responses compared with intact BLG but retained significant responses in PBMCs from some patients with cow's milk allergy. Hence, chymotrypsin-digested BLG peptides are a possible tool for immunomodulation therapy in some patients with cow's milk allergy,

\section{Acknowledgements}

This study was funded in part by the Research and Development Program for New Bio-industry Initiatives (2005 2009) of the Bio-oriented Technology Research Advancement Institution (BRAIN), Japan.

\section{References}

1. Saarinen KM, Juntunen-Backman K, Jarvenpaa AL, et al. Supplementary feeding in maternity hospitals and the risk of cow's milk allergy: a prospective study of 6209 infants. J Allergy Clin Immunol 1999;104:457-61.

2. Sampson HA. Food allergy. Part 1: immunopathogenesis and clinical disorders. J Allergy Clin Immunol 1999;103:717-28.
3. Ohman JL Jr, Findlay SR, Leitermann KM. Immunotherapy in catinduced asthma. Double-blind trial with evaluation of in vivo and in vitro responses. J Allergy Clin Immunol 1984;74: 230-9.

4. Bousquet J, Becker WM, Hejjaoui A, et al. Differences in clinical and immunologic reactivity of patients allergic to grass pollens and to multiple-pollen species. II. Efficacy of a double-blind, placebocontrolled, specific immunotherapy with standardized extracts. J Allergy Clin Immunol 1991;88:43-53.

5. Pecquet S, Bovetto L, Maynard F, Fritsche R. Peptides obtained by tryptic hydrolysis of bovine beta-lactoglobulin induce specific oral tolerance in mice. J Allergy Clin Immunol 2000;105:51421.

6. Fritsche R, Pahud JJ, Pecquet S, Pfeifer A. Induction of systemic immunologic tolerance to beta-lactoglobulin by oral administration of a whey protein hydrolysate. J Allergy Clin Immunol 1997; 100:266-73.

7. Kondo N, Agata H. Fukutomi O, et al. Lymphocyte responses to food antigens in patients with atopic dermatitis who are sensitive to foods. J Allergy Clin Immunol 1990;86:253-60.

8. Patriarca G, Nucera E, Roncallo C, et al. Oral desensitizing treatment in food allergy: clinical and immunological results. Aliment Pharmacol Ther 2003;17:459-65.

9. Standring R, Lavender EA, Wheeler AW, et al. Induction of Thelper cell activity by fragments of rye grass pollen extract produced by digestion with chymotrypsin. Int Arch Allergy Appl Immunol 1988;87:337-41.

10. Ferguson TA, Peters T Jr, Reed R, et al. Immunoregulatory properties of antigenic fragments from bovine serum albumin. Cell Immunol 1983;78:1-12.

11. Litwin A, Pesce AJ. Fischer T, et al. Regulation of the human immune response to ragweed pollen by immunotherapy. A controlled trial comparing the effect of immunosuppressive peptic fragments of short ragweed with standard treatment. Clin Exp Allergy 1991;21:457-65.

12. Pecquet S, Bovetto L, Maynard F, Fritsche R. Peptides obtained by tryptic hydrolysis of bovine beta-lactoglobulin induce specific oral tolerance in mice. J Allergy Clin Immunol 2000;105:51421.

13. Fritsche R, Pahud JJ, Pecquet S, Pfeifer A. Induction of systemic immunologic tolerance to beta-lactoglobulin by oral administration of a whey protein hydrolysate. J Allergy Clin Immunol 1997; 100:266-73.

14. Takahashi I, Nakagawa I, Kiyono H, et al. Mucosal T cells induce systemic anergy for oral tolerance. Biochem Biophys Res Commun 1995;206:414-20.

15. Hashimura S, Fujikawa Y, Enomoto A, et al. Differential inhibition of $\mathrm{T}$ and $\mathrm{B}$ cell responses to individual antigenic determinants in orally tolerized mice. Int Immunol 1994;6:1791-7.

16. Hoyne G, Callow M, Kuo M, Thomas W. Inhibition of T-cell responses by feeding peptides containing major and cryptic epitopes: studies with the Der p1 allergen. Immunology 1994;83: $190-5$.

17. Rudensky Ayu, Preston-Hurlburt P, Hong SC, et al. Sequence analysis of peptides bound to MHC class II molecules. Nature 1991;353:622-7.

18. Mowat A. The regulation of immune responses to dietary protein antigens. Immunol Today 1987;8:93-8. 
19. Kondo N, Fukutomi O, Agata $\mathrm{H}$, et al. The role of $\mathrm{T}$ lymphocytes in patients with food-sensitive atopic dermatitis. J Allergy Clin Immunol 1993;91:658-68.

20. Inoue $\mathrm{R}$, Matsushita $\mathrm{S}$, Kaneko $\mathrm{H}$, et al. Identification of betalactoglobulin-derived peptides and class II HLA molecules recognized by $\mathrm{T}$ cells from patients with milk allergy. Clin Exp Allergy 2001;31:1126-34.

21. Sakaguchi $\mathrm{H}$, Inoue $\mathrm{R}$, Kaneko $\mathrm{H}$, et al. Interaction among human leucocyte antigen-peptide-T cell receptor complexes in cow's milk allergy: the significance of human leucocyte antigen and $\mathrm{T}$ cell receptor-complementarity determining region 3 loops. Clin Exp Allergy 2002;32:762-70.

22. Suzuki K, Inoue R, Sakaguchi $H$, et al. The correlation between ovomucoid-derived peptides, human leucocyte antigen class II molecules and $\mathrm{T}$ cell receptor-complementarity determining region 3 compositions in patients with egg-white allergy. Clin Exp Allergy 2002;32:1223-30.

23. Hong SJ, Michael JG, Fehringer A, Leung DY. Pepsin-digested peanut contains T-cell epitopes but no IgE epitopes. J Allergy Clin Immunol 1999;104:473-8.
24. Kaneko S, Furutani K, Koro O, Yamamoto S. Transient shift toward $\mathrm{T}$ helper 1 cytokine production by peripheral blood mononuclear cells following successful treatment of patients with atopic dermatitis. Allergol Int 2003;52:21-9.

25. Kondo $\mathrm{Y}$, Kakami M, Koyama $\mathrm{H}$, et al. IgE cross-reactivity between fish roe (salmon, herring and pollock) and chicken egg in patients anaphylactic to salmon roe. Allergol Int 2005;54:31723.

26. Kondo N, Fukutomi O, Shinbara M, Orii T. Inhibition of interferon-gamma and interleukin-2 production from lymphocytes stimulated with food antigens by an anti-allergic drug. Tranilast, in patients with food-sensitive atopic dermatitis. Biotherapy 1994;8: 19-22.

27. Dorion BJ, Burks AW, Harbeck R, et al. The production of interferon-gamma in response to a major peanut allergy, Ara h II correlates with serum levels of IgE anti-Ara h II. J Allergy Clin Immunol 1994;93:93-9.

28. Liu T, Kohsaka H, Suzuki M, et al. Positional effect of amino acid replacement on peptide antigens for the increased IFN- $\gamma$ production from CD4T cells. Allergol Int 2005;54:117-22. 